\title{
Student Response Systems: a rationale for their use and a comparison of some cloud-based tools
}

\author{
Martin Compton, Jason Allen \\ University of Greenwich
}

Take any lecture or seminar and monitor student verbal responses to questions or contributions to discussions and the likelihood is that a few students will dominate. Others will contribute rarely and many will not contribute at all unless deliberately targeted by the lecturer. Technological solutions to widening participation in face-to-face taught sessions include 'Student Response Systems' (SRS). These are also referred to in the literature as 'Classroom Response Systems' (CRS), 'Audience Response Systems' (ARS) or, simply, 'voting tools' or sometimes 'clickers'. Throughout we use the terms SRS or cloud-based 'tools' as these are the most common terms in our context. Some tools focus on providing an interface for answering questions (from multiple choice to open text), whilst others include student question-asking, voting, rating and discussion options. This article sets out to offer an analysis of six SRS web-based systems that can be used for free (though most have premium options), using a common analytical framework. It should be noted that there are dozens of such tools available, but these have been selected as they represent what we consider to be the best of various types of web-based SRS. Our conclusions are based primarily on functionality and ease of use, as detailed in the analyses set out below. Each tool has its own unique selling point/s (USP), which we have also highlighted.

Although our University has embraced the concept of digital first and connectedness as core principles of $21^{\text {st }}$ century teaching and learning, concerns and doubts are often heard in relation to this. The proliferation of mobile devices is often seen as a negative, particularly in terms of their distraction potential. The tendency towards divergent functionality of device types and a range of potential ethical issues (Traxler, 2010) could well be seen as a reason to discourage or even ban mobile devices in lectures and seminars (Brenner, 2015).

Academics have legitimate concerns about the use of mobile devices, especially their potential to distract students in lectures. Yet the extent of proliferation, the impracticality of and likely resistance to - policing of device mis/use and the existing widespread use of such devices for other academic activity, by students and academics alike, make for conditions well suited to their appropriation in classrooms and lectures (Balakrishnan and Lay, 2013). Such appropriation aligns with our broad institutional support for the principles that underpin 'BYOD' (Bring your own device) which seeks to exploit the potential of the expensive and powerful devices many, if not most, of our students carry with them on a daily basis.

Taking control, in effect, of the devices by embedding their use at different stages of a lecture or seminar, is one way to minimise temptation towards distraction while maintaining other benefits afforded by mobile device use, such as note-taking and language support. One of the authors has delivered CPD sessions which have highlighted the potential of the tools analysed below across the University. Colleagues who have then gone on to use one or more of them have reported real benefits in using SRS because they provide continuing opportunities for interaction. For example: students can pose questions as well as answer them; individuals or groups can post text wall comments; the lecturer can utilise slide management options to focus attention in different ways. Many colleagues have made a 


\section{Technology Reviews}

point of saying how they have achieved this despite perceiving themselves as anything but 'tech savvy'.

Early SRS were dependent on the use of sets of 'clickers' (physical voting devices that were issued to students at the start of a lecture). Like their more recent internet-based (more typically referred to as 'cloud-based') and mobile device-dependent counterparts, reported benefits include improvements in academic achievement (Kay and LeSage, 2009), instant feedback to the lecturer on breadth of understanding (Keough, 2012) and higher levels of engagement and satisfaction (Hedgcock and Rouwenhorst, 2014). Other benefits include: engagement through 'fun' and student-student / student-lecturer dialogue (Blasco-Arcas et al., 2013); boosting attendance and providing opportunities for reflection (Bojinova and Oigara, 2011); the promotion of active and student-centred elements in a didactic environment (Caldwell, 2007). Clicker options can often be subject to practical barriers to their use, not least the fact that initial costs of device purchase and installation can be high (Hedgcock and Rouwenhorst, 2014). Whilst many of the reliability issues have been resolved since clickers first appeared in the 1960s, frustration with establishing connections (Kay and LeSage, 2009) and equipment failure (Hedgcock and Rouwenhorst, 2014) remain a concern - this is one reason why our institution has focused on surveying options that are cloud-based and are BYOD dependent. The main concerns related to cloud-based solutions are the strength and capacity of Wi-Fi in large lecture spaces and students' willingness to use their own personal devices.

As with all technology used to support teaching and learning, it is the underpinning pedagogy that should drive the choice of tool and the way in which it is used (Beetham and Sharpe, 2013). When using SRS, lecturers need to understand and be able to articulate their goals and be suitably prepared, since wasted time and questionable relevance will reduce student commitment to participation (Nielsen et al., 2013). Whilst it is not the goal of this article to discuss pedagogy, it is worth sharing the question that we ask ourselves whenever we are thinking about deploying a SRS: "What does it add in terms of engagement, interaction or communication that couldn't be achieved using traditional approaches?"

We spent some time looking at and trialling a range of SRS options. Each needed to offer lecture/seminar interaction potential and be free or available on a 'freemium' basis (i.e. available for trial with paid add-ons or extensions to functionality; the free elements are designed to attract a proportion of users to purchase premium options). To evaluate these tools, our criteria were: their potential for engagement and participation (a challenge to passive pedagogic approaches) and how easy they were for staff and students to use. The next section gives brief summaries of each SRS system. Each of these is followed by a summary of key points found in our analysis of the tools by means of the 'SCORE' system (Graves, 2008), which we have interpreted and adapted as set out below. SCORE is a response to perceived inadequacies of the 'SWOT' (Strengths, Weaknesses, Opportunities, Threats) analytical model and, given the opportunity to construe the model according to our own needs and criteria, we have found it an effective analytical and comparison tool that may also be applied in future to other technology or educational resource reviews.

Each element of SCORE represents the following aspects of our reviews:

Strengths: We interpreted these as perceived good points, effective aspects of the tool and, where relevant, any unique (or unusual) selling points. 
Challenges: Here, we focus on limitations to the tool itself and also include key constraints in its use - from both lecturer and student perspectives.

Options: All the tools here are either free or work on a freemium model. Some tools limit the number of students in the free version (e.g. Zeetings), whilst others limit the number of polls or questions you can use per presentation (e.g. Slido/ Mentimeter). As many SRS have institutional markets in mind, they offer a broad range of licences and packages - appropriate to the needs of every buyer from individual to whole institution and costing from a few pounds to tens of thousands. It would be impossible to capture the breadth of this but we have tried to highlight those aspects of functionality incurring cost that we consider to be of most potential value/relevance to academic users.

Responses: In the original SCORE model this refers to the response by the outside world to the strategy under review. For the purposes of this paper we have here focused on what it offers in terms of student engagement.

Effectiveness: These comments, both by the review team and arising from discussions with colleagues who have trialled the tools in question, are inevitably subjective. Such aspects as relevance to different contexts, efficiency, reliability, elegance, appropriateness and potential for integration with core systems (e.g. the Virtual Learning Environment) have guided our brief conclusions.

Below are our SCORE analyses of Todaysmeet, Slido, Polleverywhere, Mentimeter, Socrative, Kahoot and Zeetings. 


\section{Todaysmeet (https://todaysmeet.com/)}

The Todaysmeet strapline is ' Enhance classrooms. Enable discussions. Empower students.' It is designed to act as a 'backchannel' to any taught session, providing a secondary layer of discussion or conversation to the topic. Of all the tools, it has the fewest functions, but that means it is simple to use. It is primarily a 'text wall' system that can be used either synchronously in taught sessions or for collaboration and discussion outside of face-to-face classes. Students go to a unique web address (URL) provided by the lecturer or scan a Quick Response (QR) code with their mobile device (if they have a free QR scanning app enabled).

\begin{tabular}{l} 
Open a new room \\
Pick a name \\
MyRoom \\
Keep the room open for \\
one week \\
Who can join? \\
Anyone \\
Logged-in users \\
My School \\
Password [?] \\
\hline Open your room \\
\hline
\end{tabular}

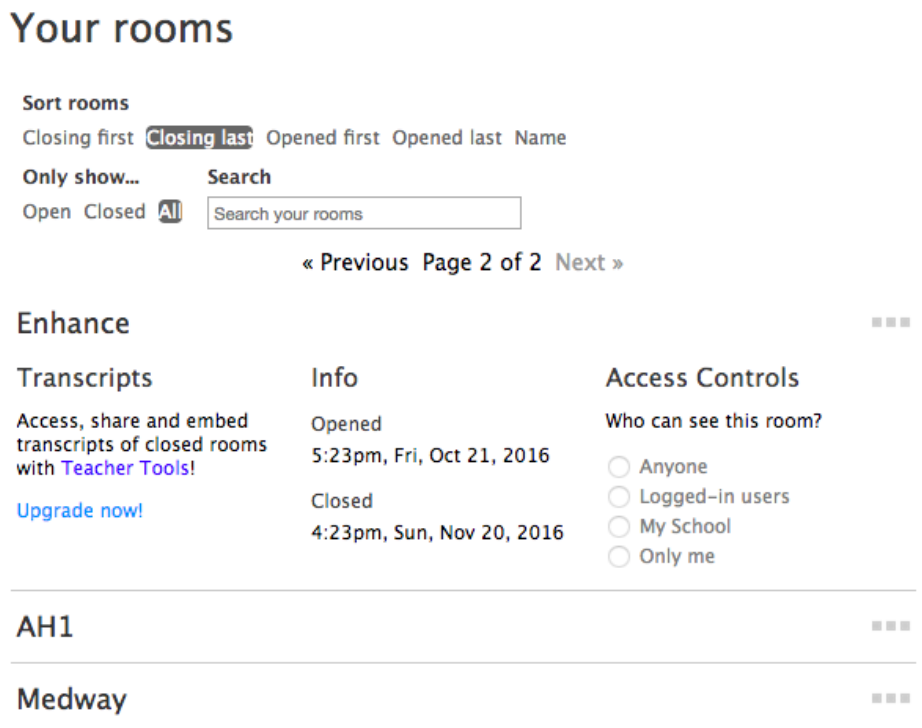

Figure 1: Todaysmeet lecturer window, showing options and records.

\section{TodaysMeet}

TM

Listen

Acts as a 'backchannel'
less than a minute ago by Matt
Type up to 140 characters
less than a minute ago by Matt
This is what the room looks like.
less than a minute ago by Matt

Acts as a 'backchannel'

less than a minute ago by Matt

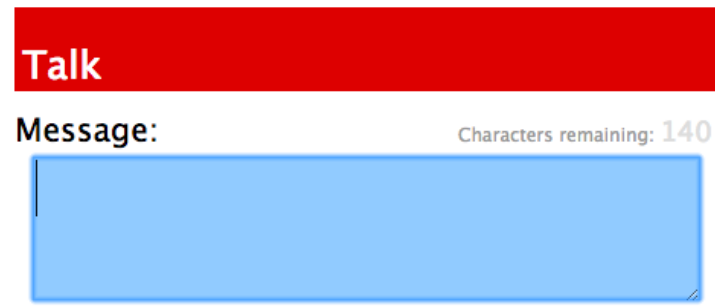

Say

Figure 2:Todaysmeet student interface. Students type in the blue box and their message appears at the top of the contributions. The responses can be displayed full screen. 


\section{Todaysmeet SCORE}

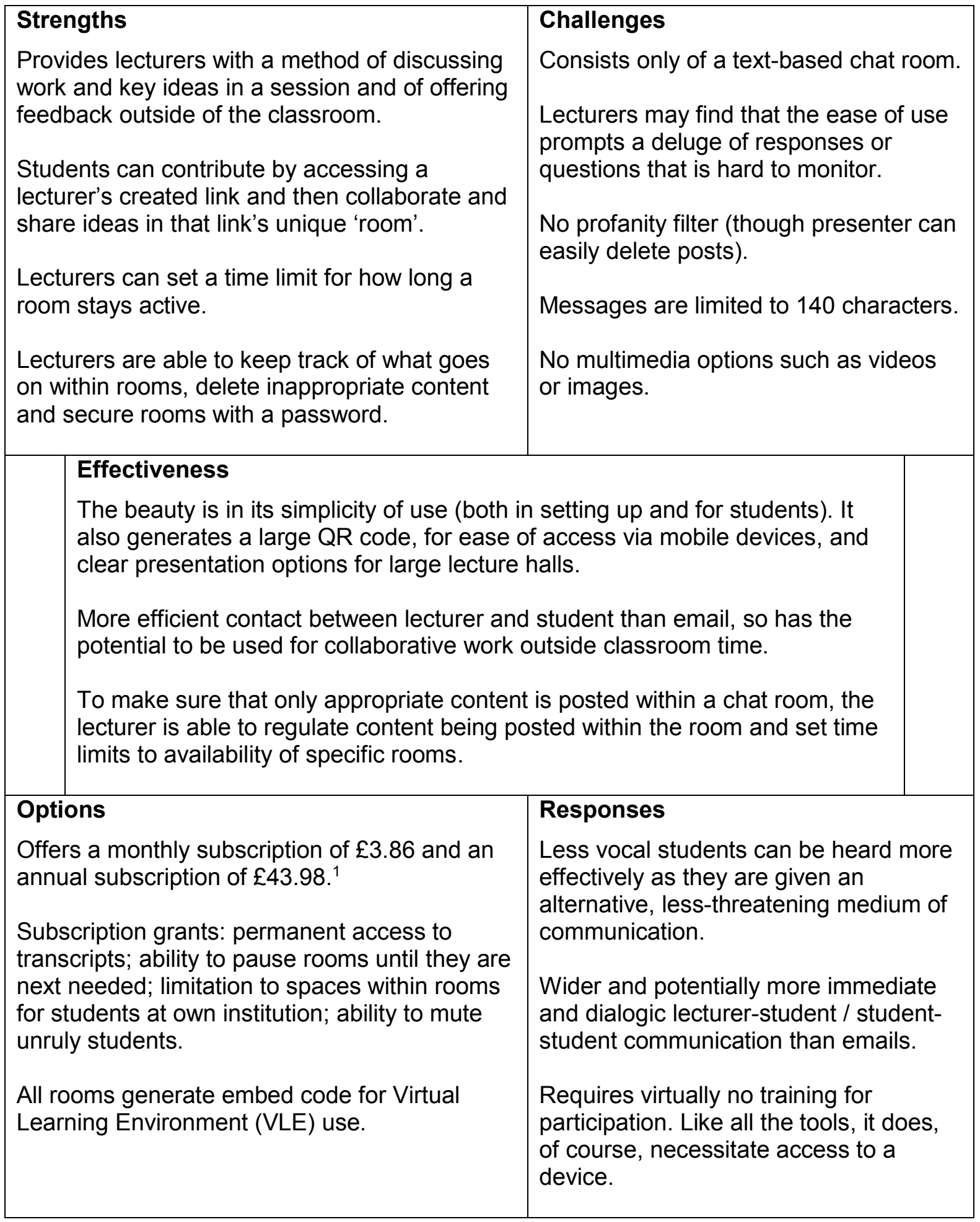

${ }^{1}$ All prices and URLs current as of 27 September 2017 


\section{Slido (https://www.sli.do/)}

Slido (or Sli.do) is promoted as a conference/event interaction tool. It is designed primarily with smart phones and tablets in mind and offers both polling and options for the audience to ask questions of the event hosts which can be 'upvoted' in the free account (i.e. other students can show approval or agreement with questions and the most popular are pushed to the top of the list) or downvoted (pro accounts only). Students go to the standard URL (above) and enter a unique 'event code'.

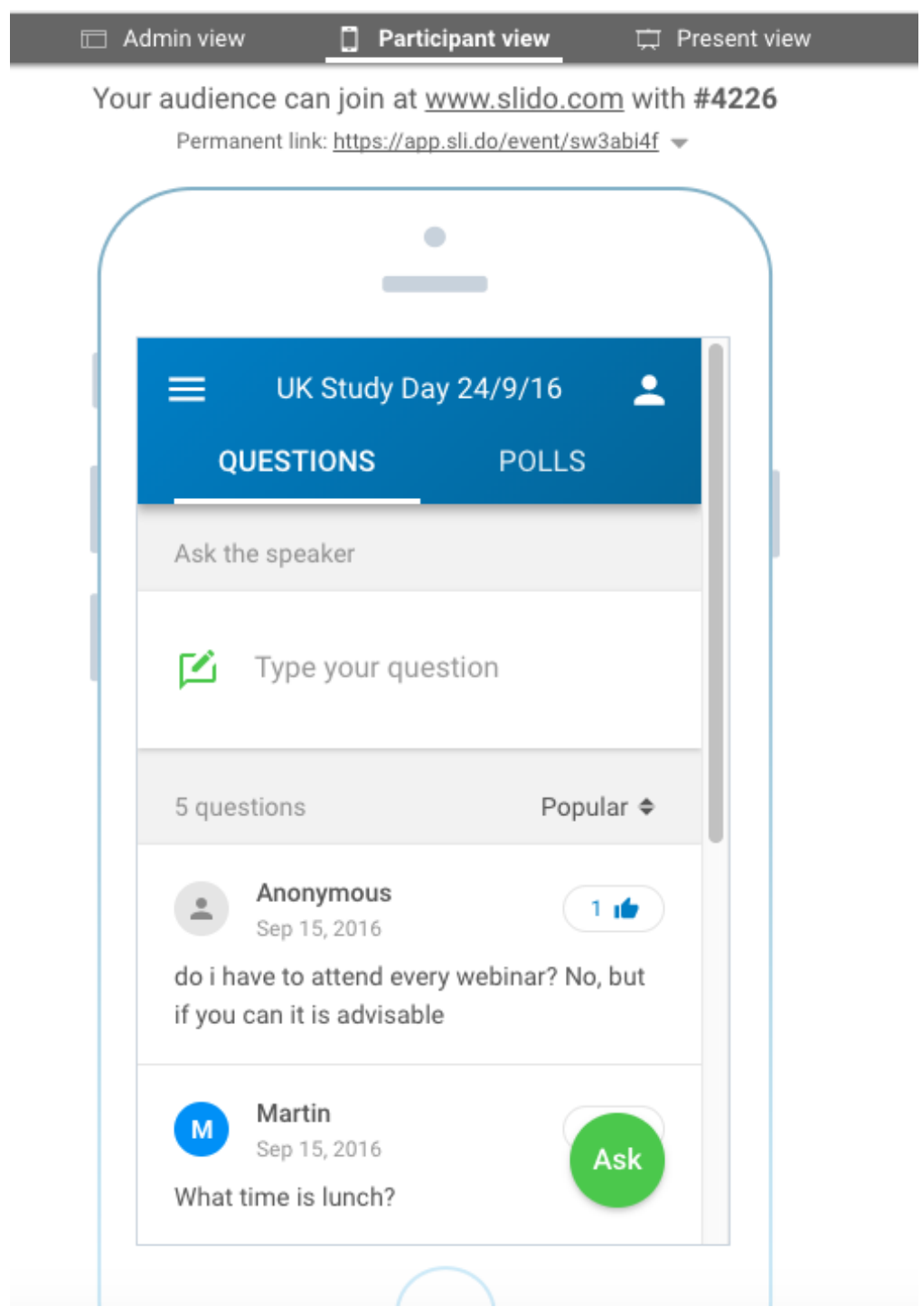

Figure 3: Slido screen as it appears on a mobile device for students. The 'questions' are those that the students ask the lecturer and the 'polls' those asked by the lecturer. Note the 'Admin' (i.e. lecturer) and 'Present' views and the joining instructions. These are much larger in 'Present' mode. 


\section{Slido SCORE}

\begin{tabular}{|c|c|}
\hline $\begin{array}{l}\text { Strengths } \\
\text { Polls can be set up within a matter of minutes } \\
\text { and be in multi-choice, open-text or ranking } \\
\text { formats. } \\
\text { Lecturer can prioritise questions voted by large } \\
\text { proportions of students. } \\
\text { Enhances interaction with less vocal students. } \\
\text { Lecturer is able to test and show the interface of } \\
\text { event from the viewpoint of students. }\end{array}$ & $\begin{array}{l}\text { Challenges } \\
\text { There is no moderation control on free } \\
\text { accounts. } \\
\text { Free account offers unlimited events } \\
\text { but only three polls per event. } \\
\text { Many of the services available within } \\
\text { Slido are unusable by free accounts } \\
\text { and costing per event and payment } \\
\text { plans are quite expensive. } \\
\text { Switching between lecturer view, } \\
\text { student view and presentation (of poll } \\
\text { results) is tricky initially. }\end{array}$ \\
\hline \multicolumn{2}{|c|}{$\begin{array}{l}\text { Effectiveness } \\
\text { Once the lecturer is comfortable with the system, the combination of } \\
\text { polling and question-asking is very effective and works especially well } \\
\text { with very large groups. } \\
\text { Requires lecturers to switch between presentation tools used and the } \\
\text { Slido interface which can hinder session fluency. }\end{array}$} \\
\hline $\begin{array}{l}\text { Options } \\
\text { One time (Private } £ 119 \text {, Pro } £ 199 \text {, Premium } \\
£ 599 \text { ), and Edu (Lecturer } £ 50 \text {, Department } \\
£ 125 \text {, Institution £325) payment plans available. } \\
\text { Discounted payment plan for educational } \\
\text { institutions. } \\
\text { 'Down voting' feature in paid accounts allows } \\
\text { both lecturers and students to regulate } \\
\text { questions added to an event. } \\
\text { Twitter integration can be implemented by } \\
\text { identifying an event hashtag in all accounts. } \\
\text { Event analytics and instant infographic } \\
\text { generation available in all accounts, but surveys, } \\
\text { video-embedding, data exports, support and } \\
\text { branding only with Pro and Premium accounts. }\end{array}$ & $\begin{array}{l}\text { Responses } \\
\text { Encourages good responses from the } \\
\text { less vocal students and some features } \\
\text { (e.g. word cloud generation) prompt } \\
\text { additional interaction once one or two } \\
\text { people have begun contributing. } \\
\text { Depending on audience, the ability to } \\
\text { self-moderate questions is open to } \\
\text { abuse. This feature does heighten } \\
\text { levels of engagement, however. } \\
\text { Assists in keeping the attention of } \\
\text { students through the use of polls which } \\
\text { can be set up while presenting. }\end{array}$ \\
\hline
\end{tabular}




\section{Polleverywhere (https://www.polleverywhere.com/)}

Polleverywhere is a United States-based lecture and event interaction system. Students can respond by text message or via a unique (to the lecturer) Polleverywhere link, which remains the same when the lecturer changes the poll in the lecturer area. Alternatively a range of poll types can be embedded into presentation software (PowerPoint, Keynote or Google slides).

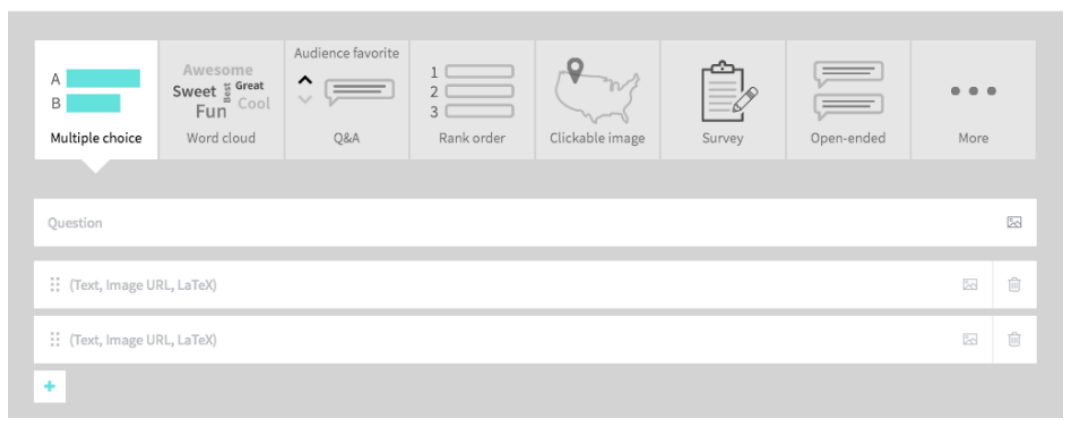

Figure 4: Poll creation window. Note options including 'clickable image', which is a unique element.

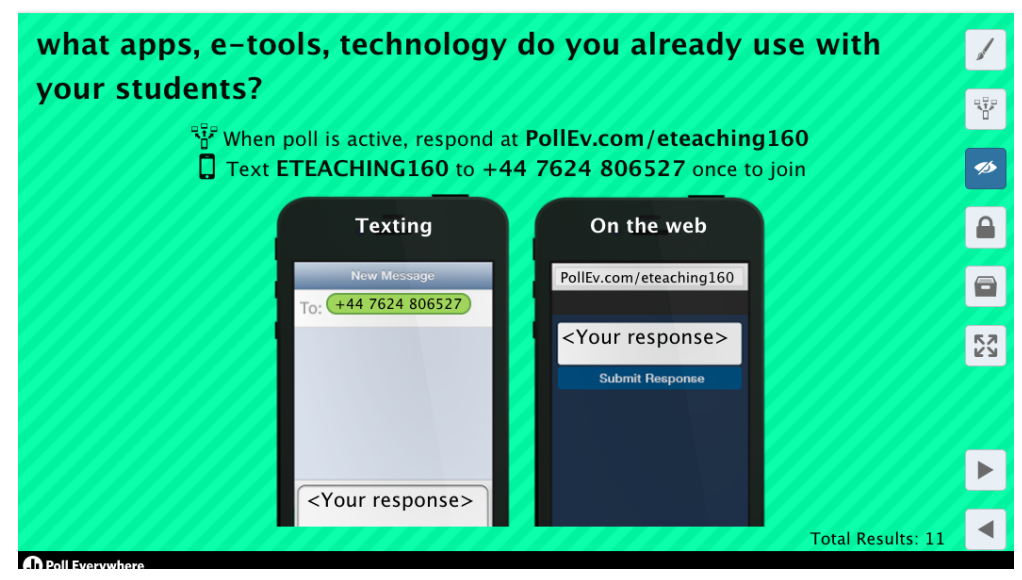

Figure 5: Poll settings and options with display showing instructions for students. Note text messaging option, along with standard URL response space online. Single URL (rather than access code) means each new question has to be activated.

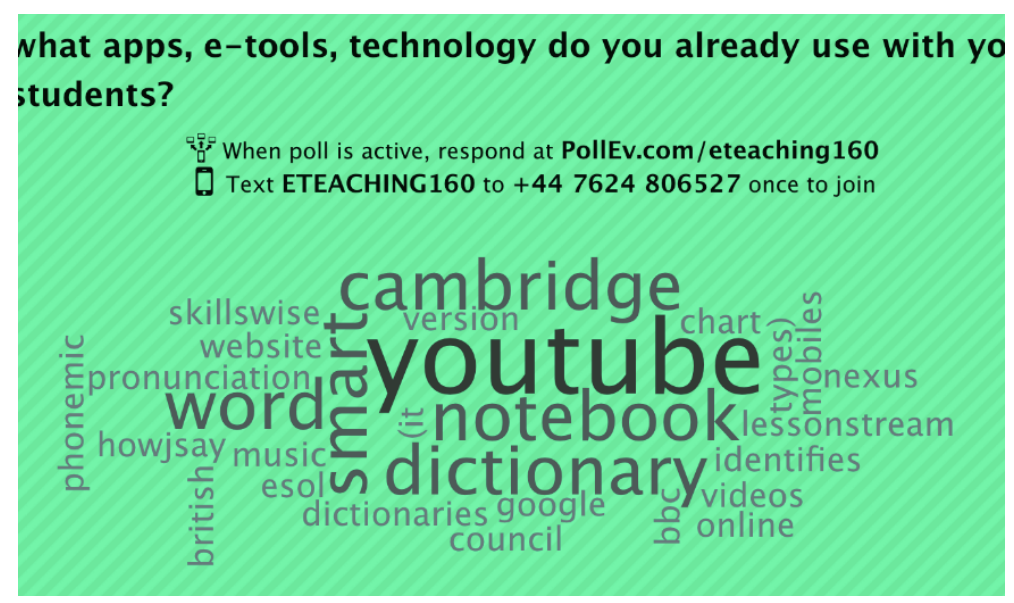

Figure 6: Sample output display. This is the word cloud option. 


\section{Polleverywhere SCORE}

\section{Strengths}

Offers the students alternatives to participating in polls via a text message.

Offers several variations to gather quantitative data from the audience and plugins that allow the lecturer to integrate polls within PowerPoint and Google slides.

Lecturer is able to add additional polls while presenting via the polls tab.

Lecturer has full control over how many times a student can respond to a poll as well as whether they can access polls anonymously.

Lecturer has control over when a student will see a question as well as being able to set a time limit for when the poll locks.

\section{Challenges}

Free version offers no method of moderation.

Basic free plan limits the number of responses to twenty-five, and the higher education edition limits the number of responses to forty, though there is no limit to the number of polls a lecturer using a free account can create.

When further questions need to be added during a presentation, having to navigate to the poll interface may disrupt the flow of the presentation.

Limited multimedia options.

\section{Effectiveness}

Integrations with PowerPoint and Google Slides plugin offer more flexibility to this SRS, though may be subject to institutional download policies and software versions.

Lecturer can keep a record of entries received from polls through a downloadable Excel file.

The look and feel as well as the range of poll types (some of which are particularly creative and engaging) make this a very attractive option.

\section{Options}

Offers customised, institution-wide options as well as a student and instructor payment plans:

Student 'Pays' ( $£ 10$ annually per student where responses are class-size-limited) or Instructor ( 251 per semester, 400 responses per poll username). Both options add a range of question types, live word clouds, text walls, customised look and styles, correct answer display, reporting and grading team competitions, moderation, automatic censoring, custom keywords, VLE integration, share polls among lecturer options, FAQ and email support.

\section{Responses \\ The different variations of poll activities provide methods of maintaining students' attentions for longer periods of time. \\ Offers rating activities that assist the lecturer in prioritising topics the audience is most interested in, as well as in gaining a better understanding of the overall mood of the audience. \\ Icebreaker activities offer a smoother transition into group-based activities among students and build confidence in use of the tool itself by students.}




\section{Mentimeter (https://www.mentimeter.com/)}

Mentimeter is another meetings, events and lecture interaction tool; the company is based in Sweden. Unlike other tools it is designed so that it can be used synchronously in taught sessions (students go to the standard menti.com link and enter a room code which is generated by the lecturer) or asynchronously via a permalink so that responses can be entered at any time and Mentimeter can then act as a research tool.

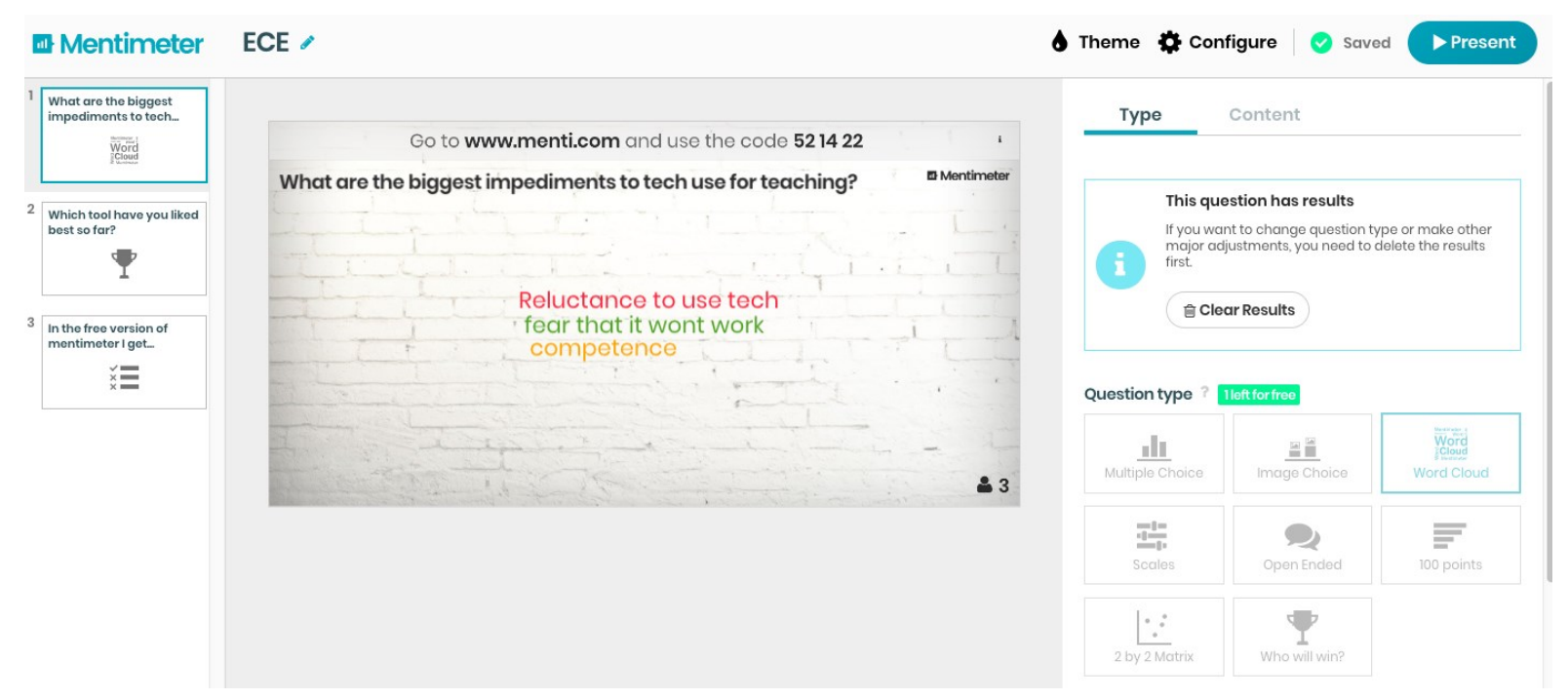

Figure 7: Mentimeter lecturer window showing question format options, numbers of questions available (limited in free account) and formatting/configuration options. It is also possible to insert unlimited slides via this window. When ready, the slides/ questions are launched using the 'present' button which displays the first slide.

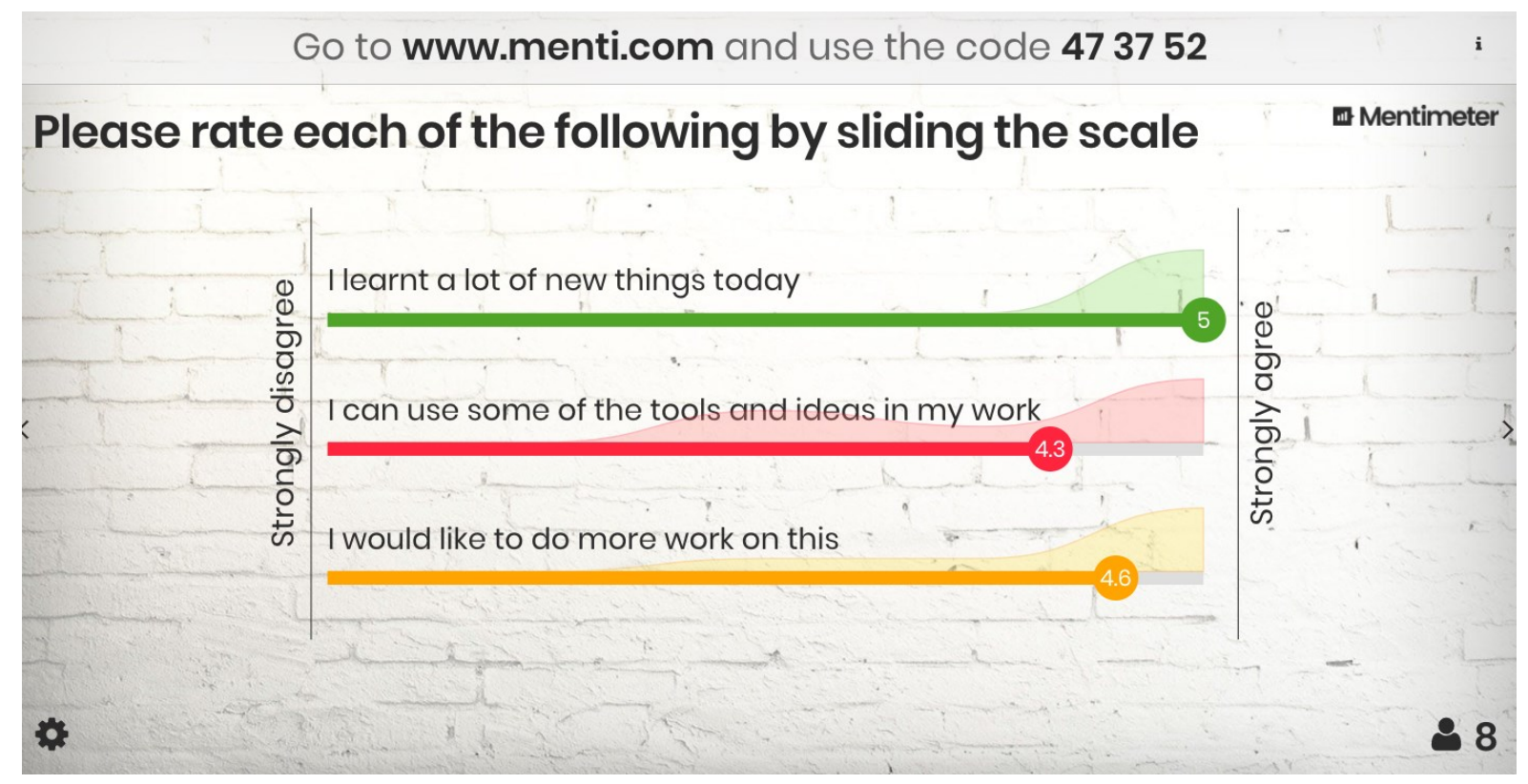

Figure 8. In presentation mode, the screen displays the active poll or question and the results (choice between immediate display or delayed allowing time for all contributors to comment without being influenced by others). Note the number of students (bottom right), the navigation arrows (either side) and the joining instructions at the top. 


\section{Mentimeter SCORE}

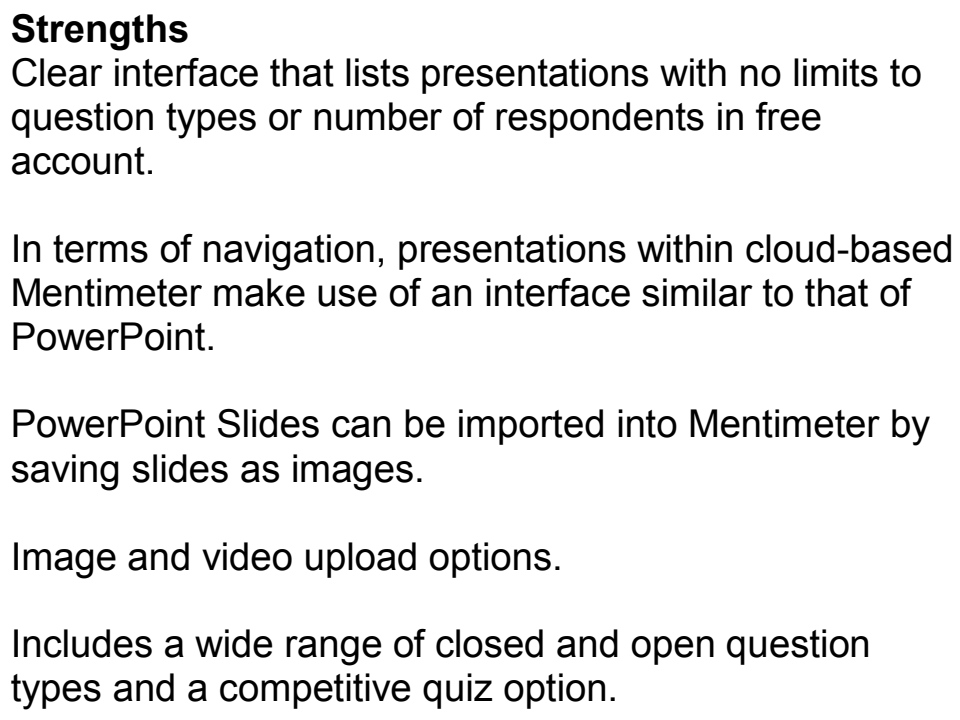

PowerPoint Slides can be imported into Mentimeter by saving slides as images.

Image and video upload options.

Includes a wide range of closed and open question types and a competitive quiz option.

\section{Challenges}

Mentimeter PowerPoint

integration limits lecturer to 5

Mentimeter questions.

On free accounts, lecturers are limited to two poll activities and five quiz questions (an additional poll and question can be 'earned' by e-mailing a recommendation to a colleague).

Branding and colours may be customised only through a paid subscription.

\section{Effectiveness \\ In our view the easiest quiz-authoring system of the all the SRS tools that have multiple question formats. \\ Moderation and profanity filters (multi-language) as standard and option of presenter or audience-paced responses. \\ Particularly effective where basic slide information is needed to contextualise interactions and even more effective when embedded into online presentation tool or plugin is used in PowerPoint. Both of these negate the need to switch between presentation and SRS. \\ Instructional material for lecturers and support are very good.}

\section{Options}

In addition to locally-negotiated, institution-wide options, Mentimeter offers a range of priced options for single-user educational accounts from $£ 3.50-£ 15.40$ per month. The basic package includes:

unlimited audience size, anonymous voting, quizzes for students, unlimited questions, security and privacy, export results, tech support.

Site licences can add the ability to customise style, share lecturer presentations across accounts, branding and advanced visualisations.

\section{Responses}

'Reaction' feature is quick method of testing classroom engagement - this feature can be used to see who in the classroom agrees or disagrees with a displayed statement.

Familiar social media icons can be activated by the lecturer and used by students to show engagement, enjoyment, confusion etc.

Very varied integration types including a student opinion/ questions to lecturer option.

Through the use of asynchronous open-question activities, it is possible to gain insight into student views or use it as a research tool which allows for comparison and cross referencing of data. 


\section{Socrative (https://www.socrative.com/)}

Socrative is a quiz tool that pushes the gamified approach and lecturers use their own space to create quizzes. The tool generates a unique room number for students which is accessed through the standard URL above. It is optimised for smart phone and tablet use and, although authoring can be fiddly, the student experience is simple and intuitive.

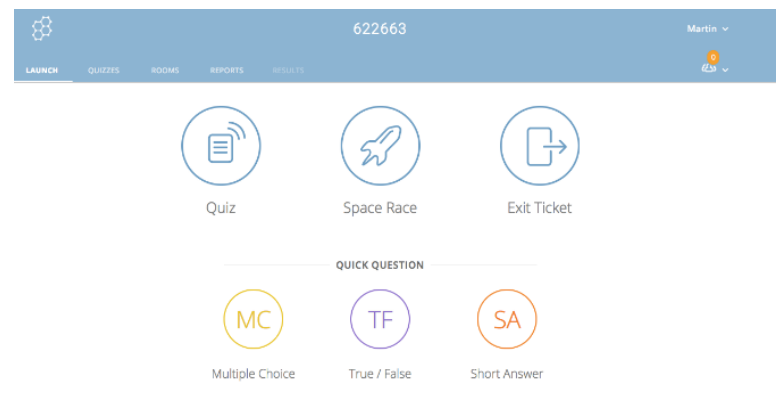

Figure 9: Socrative 'Lecturer' app showing quiz options. Note the ad hoc 'MC', 'TF' and 'SA' which enable the tool to be used for unplanned, verbally-delivered questions.

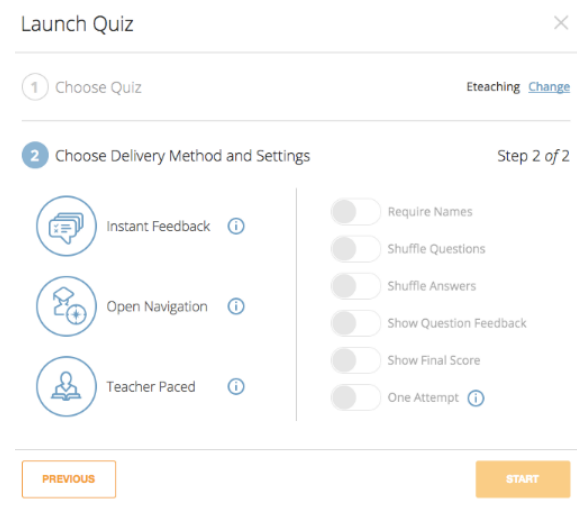

Figure 10: Socrative Lecturer options

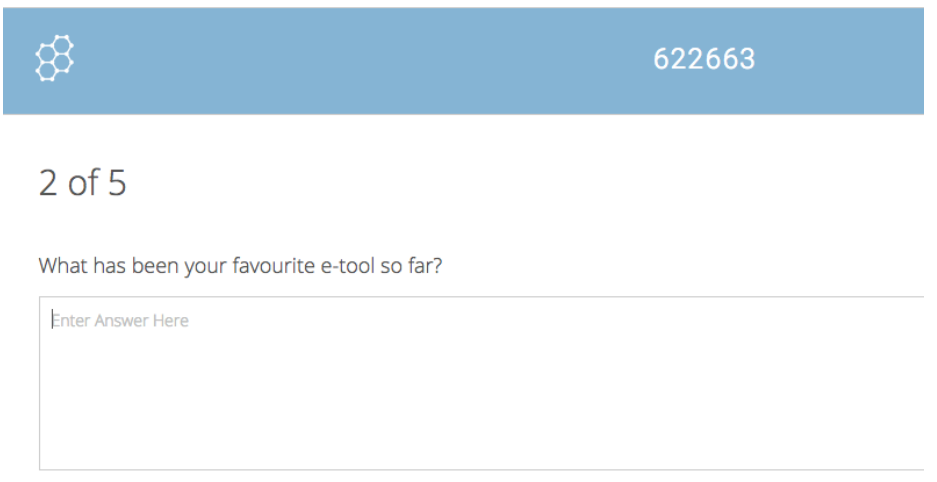

SUBMIT ANSWER

Figure 11: Socrative Student app. This is accessed via a separate link (or different mobile app) and the quiz is accessed via an access code unique to the lecturer. 


\section{Socrative SCORE}

\section{Strengths}

Use of gamification elements designed to increase excitement, fun and class engagement.

In the event of repeating quiz-based activity, lecturer can alter the order of questions, to see what students have picked up.

Lecturer is quickly able to develop quiz-based activities online, or offline through an Excel spreadsheet.

Possible to check classroom engagement through quick-question activities, which can be set up during a lecture.

Offers immediate post-quiz emailing of results to lecturer.

\section{Challenges}

Activities are limited to quiz-based activities only, which get repetitive.

No system in place that allows students to ask questions in relation to quizzes.

Only one activity can be active within each room at a time.

It is perceived by some as being more appropriate to younger students and certainly has a school 'feel'.

\section{Effectiveness}

Whilst there are activities aimed at groups and individuals, implementation of multimedia features, such as video clip and audio files, is not possible.

The facility to email a report of results immediately after the quiz is particularly easy and useful if the lecturer is keen to gauge an individual student's progress. Lecturers can prepare pre-set feedback to students which is determined by the answer that the students give.

Possible to set up activities that can remain active outside the classroom.

No limits to the number of attempts students can make so can be an effective formative approach.

\section{Options}

Annual Payment of $£ 43$ in higher education institutions includes a range of additional features, tracking and email support.

Additional features within the gamified 'Space Race' activity are made available, as well as a countdown timer, shareable links and advanced data export features.

\section{Responses}

Competitiveness in response to gamified group elements often positively impacts attention and enjoyment.

Possible to keep track of student progression by reviewing their answers within reports that can be accessed online or downloaded in a range of formats.

Gives access to ten rooms, private and public. 


\section{Kahoot (https://kahoot.com/)}

Kahoot is another quizzing tool that emphasises the gamified approach. It is purely multiple choice and the entire tool is currently available free. Students access the quizzes via a unique URL (self-paced) or via the kahoot.it URL by entering a unique 'game PIN'. Students select their answer in a competitive and time-limited environment that employs colour, music and leader boards to suggest a quiz show type format.
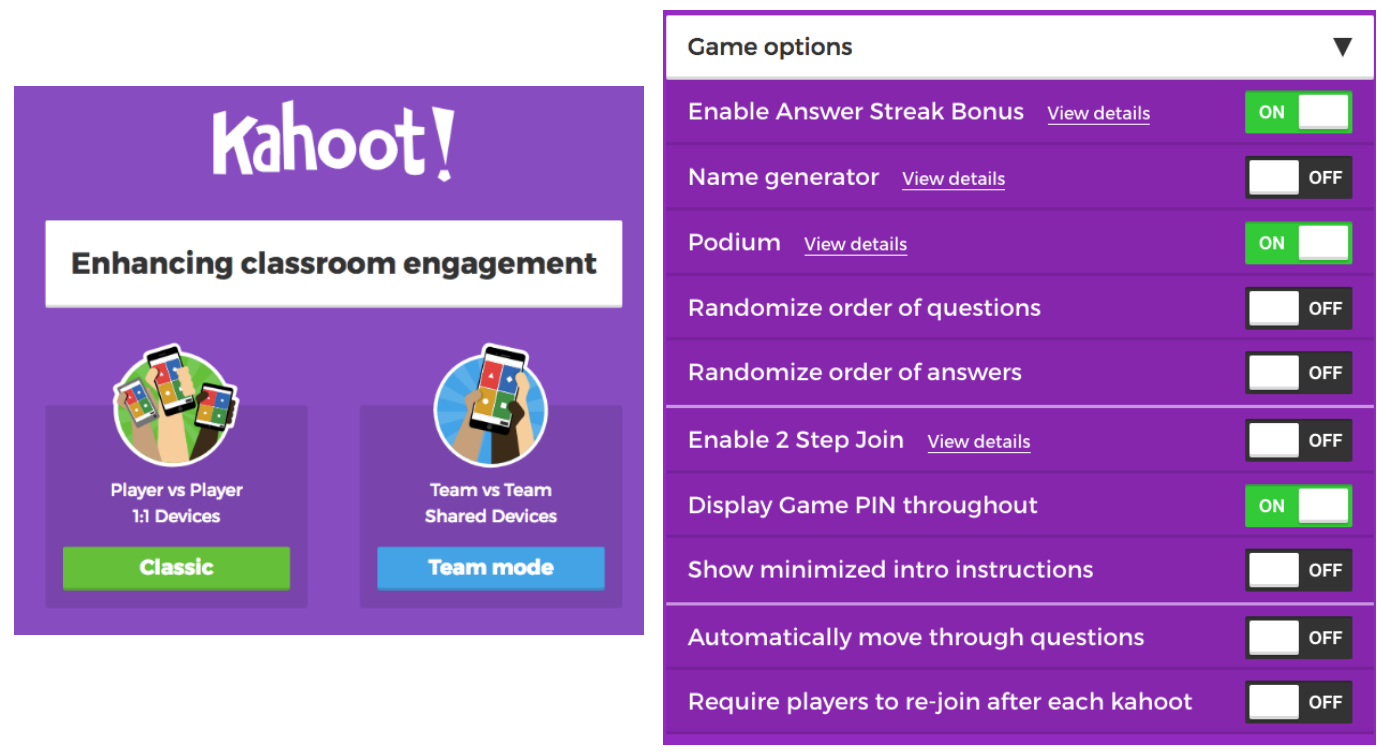

Figure 12: Kahoot lecturer launch screen (left) with options menu (above)

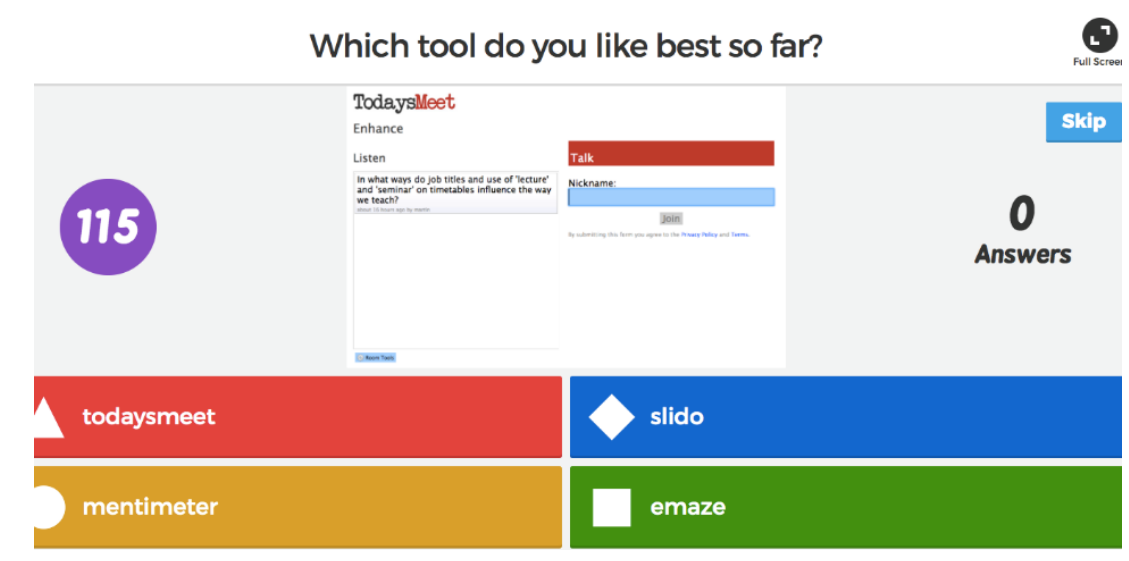

Figure 13: Screen displayed at front of class or lecture hall. Note countdown timer on left (can be set for different times). Also note that students use their own devices to vote (by colour or shape) but they do not have the questions on their devices. 


\section{Kahoot SCORE}

\section{Strengths}

Makes use of gamification elements to increase classroom engagement.

Offers two variations of quiz-based activities which focus on individual interaction.

Offers a survey activity which allows the lecturer to gain quantitative data from students.

Has a feature that allows lecturers to develop quick questions during a lecture.

Allows use of multimedia features, such as images and video within activities.

Has an interface for videos that allows lecturer to play a specific portion of a clip.

\section{Challenges}

Limited to multiple-choice questions.

Students are unable to post their own questions through the service.

Time-limit element may cause students to rush to answer questions instead of analysing them; it generates tension and anxiety and, though it certainly increases student motivation, could well have a negative impact on those with neurodiverse conditions or disabilities.

In competitive mode, the questions are displayed only on the presenter's screen, not on the students' devices.

\section{Effectiveness}

Can integrate well with media resources such as images and videos.

Can be integrated within PowerPoint through the use of third-party plugins; however this may have a detrimental impact on the overall performance of PowerPoint.

Reliant on the lecturer use of a large screen, so that questions can be seen by students.

Clearly targeted at school children, but we have seen it used very effectively with undergraduate groups.

\section{Options}

Although Kahoot has launched pilot corporate accounts and intends to monetise through premium services and solutions for corporates, there are currently no restrictions governing the services available within Kahoot.

\section{Responses}

Through gamified elements, students are more competitive and excitement is palpable.

Students are unable to see the question on their own devices which can frustrate and lead to students opting out.

Assigning groups can enhance collaboration and communication skills among students. 


\section{Zeetings (https://www.Zeetings.com/)}

Zeetings is an Australian-based tool that is relatively new to the market and offers something unique: the ability to upload slides and then insert staged interactions and video; furthermore, when accessed via a fixed lecturer URL, the slides progress at the lecturer's pace, thereby effectively taking full but unobtrusive control of the students' devices for the duration of a session. Students interact wherever the lecturer places a poll or question, but can also interact via a live discussion option and take notes in their own window.
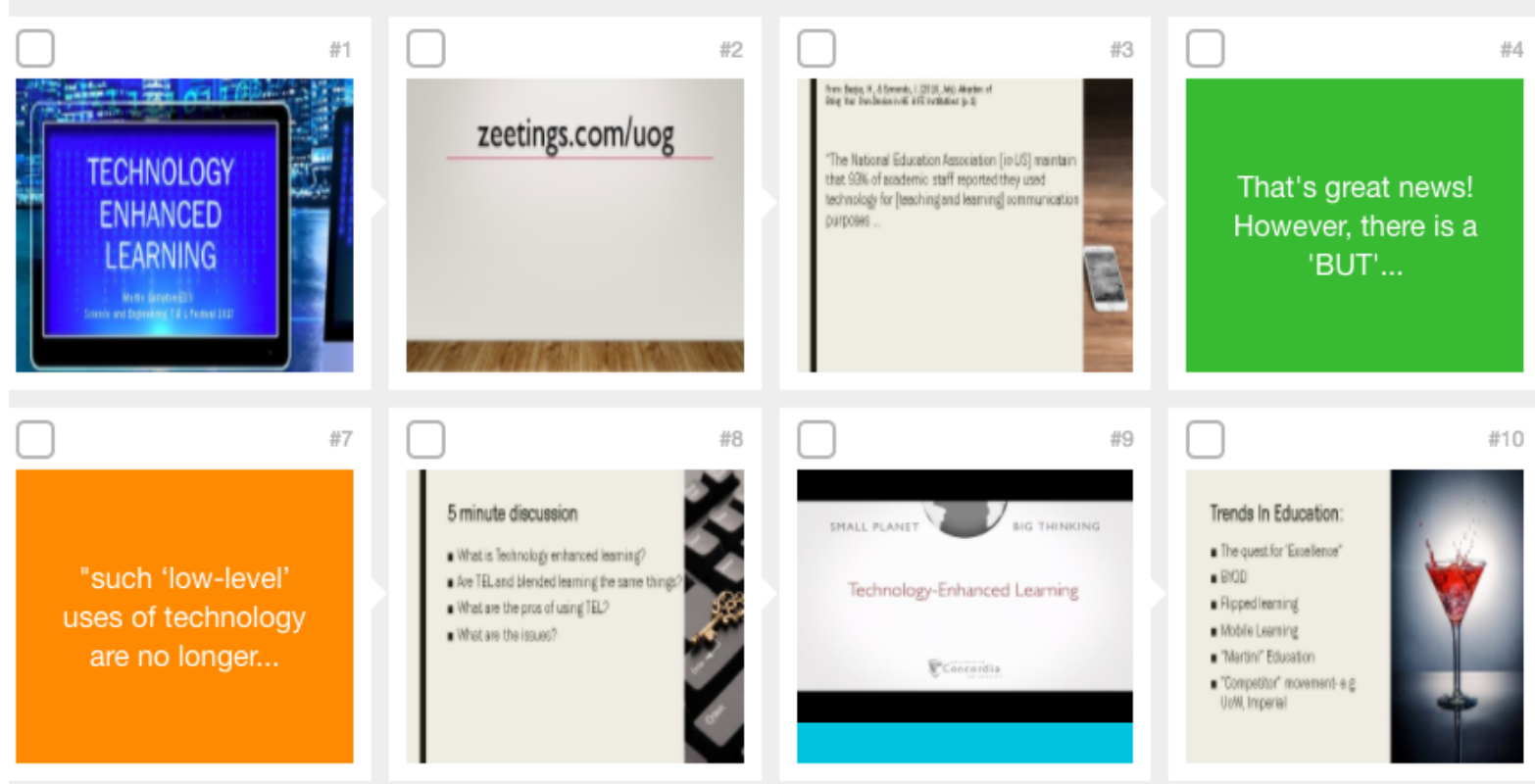

Figure 14: Zeetings lecturer interface. Slides are uploaded from PowerPoint and the interactions are then inserted in sequence. Note: YouTube videos can be inserted to run seamlessly within the slides.

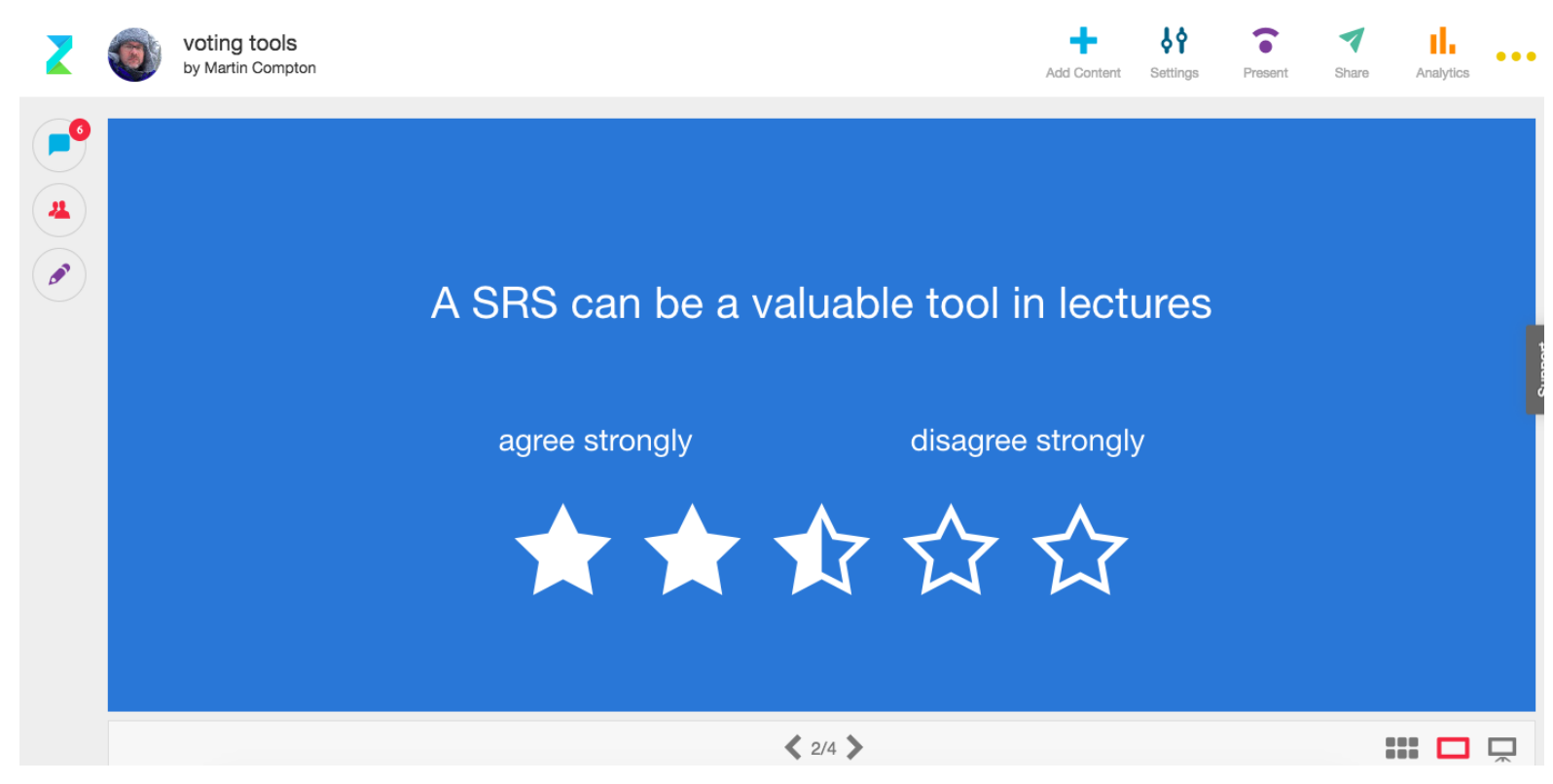

Figure 15: Zeetings interaction slide. Note the tools on the left, which include student notetaking space and optional discussion forum. The responses can be displayed as they arrive or when released by the lecturer. 


\section{Zeetings Score}

\section{Strengths}

Supports PowerPoint upload, video embedding and slide creation along with interaction in form of open text, rating and multiple choice.

Takes control of student devices by managing slide advance.

Includes a discussion forum and student notes options adjacent to slides.

Upon logging in, the lecturer can access an easy-tofollow tutorial on Zeetings' functions.

Allows lecturer to gather responses from students who did not attend the live presentation; they can move through it at their own pace.

\section{Challenges}

Limited to twenty-five students on the free version of the account.

Only three interaction types available in free account.

Individual poll responses cannot be viewed within Zeetings without an upgraded account.

Poll responses can't be exported without an upgraded account.

\begin{tabular}{|c|c|}
\hline \multicolumn{2}{|c|}{$\begin{array}{l}\text { Effectiveness } \\
\text { PowerPoint and pdf file formats can be integrated within Zeetings, but cannot } \\
\text { be edited further. Nevertheless, this feature makes the possibility of slide and } \\
\text { interaction easier than any other tool. } \\
\text { The social media icon integration, discussion and notes options, along with the } \\
\text { lecturer-controlled pacing of slides, give this tool the widest range of USPs. } \\
\text { Offers integration with a range of media resources through the use of embed } \\
\text { codes. }\end{array}$} \\
\hline $\begin{array}{l}\text { Options } \\
\text { Offers three monthly payment plans for } \\
\text { education institutions; these are: Classrooms } \\
£ 6.94 \text {, Seminars } £ 12.35 \text { and Lectures } £ 19.29 \text {. } \\
\text { Classrooms offer up to fifty students per } \\
\text { presentation, unlimited presentations, } \\
\text { advanced analytics plus exports and email } \\
\text { support. Seminars offer up to } 250 \text { students per } \\
\text { presentation and Lectures offer up to } 500 \\
\text { students per presentation. }\end{array}$ & $\begin{array}{l}\text { Responses } \\
\text { Students have a range of interaction } \\
\text { options while working at presenter pace } \\
\text { and can mail slides to themselves for } \\
\text { review after the session. } \\
\text { Students are able to post their own } \\
\text { questions to the presenter. } \\
\text { Gives students who are less vocal the } \\
\text { opportunity to be heard in multiple ways. } \\
\text { The versatility of the embed function, } \\
\text { offers more methods of holding the } \\
\text { audience's attention. }\end{array}$ \\
\hline
\end{tabular}




\section{Conclusions}

We have used all of these tools ourselves in a range of settings and have also seen them used by colleagues in situations ranging from large lectures to seminars and laboratorylocated sessions. There is no doubt in our minds that each can add to levels of engagement and interaction and, given the ease with which most, if not all, can be used to create resources, we would argue that all lecturers should be encouraged and supported in trialling at least one if they have not used such systems before. We hope that the above summaries will help colleagues decide which to use or at least prompt them to have a look at whichever has the most immediate appeal. At the time of writing, we are pushing to integrate at least one of these tools across the University, but, as individuals within the institution, we would advocate that all of the above are promoted and that their use at individual, department or even faculty level is supported with training and/or the resources supplied. Further, we would argue for licences for extended use and pro features be purchased, according to need, within faculty budgets.

Of course, care needs to be taken, whichever tool is used, to alert students to institutional policy on bullying and trolling. Our own approach is to say that comments that appear on screen will be dealt with in the same way as if someone stood up in a lecture and shouted them. Whether data exports are offered free or in paid accounts, lecturers should always attune themselves to data protection guidelines. If there is any doubt, they should encourage use of anonymity settings, pseudonyms or first names only. Above all, they should always know what they expect of students and apprise them of those expectations and of what they will be sharing. Such concerns are valid, as are continuing worries about encouraging rather than discouraging mobile device use. However, and whether we are entirely comfortable with it or not, we in higher education need to reflect the digital and engagement agendas in our delivery. We think that these tools, if chosen according to need, cohort types and pedagogic approach (and with due consideration of each lecturer's current relative comfort with technology integration), can add layers of engagement and breadth of interaction that will inject additional vigour into any taught session in any discipline.

\section{Reference list}

Balakrishnan, V. and Lay, G. C. (2013) 'Mobile wireless technology and its use in lecture room environment: An observation in Malaysian Institutes of higher learning.' International Journal of Information and Education Technology, 3(6), 634.

Beetham, H. and Sharpe, R. (2013) Rethinking pedagogy for a digital age: Designing for 21st century learning. Oxon: Routledge.

Blasco-Arcas, L., Buil, I., Hernandez-Ortega, B. and Sese, F.J. (2013) 'Using clickers in class: the role of interactivity, active collaborative learning and engagement in learning performance.' Computers and Education, 62, 102-110.

Bojinova, E.D. and Oigara, J.N. (2011) 'Teaching and learning with clickers: are clickers good for students?' Interdisciplinary Journal of E-learning and Learning Objects, 7(1), 169184. 


\section{Technology Reviews}

Brenner, T. (2015) The use of Mobile Devices in the College Classroom. Harvard University: The Derek Bok Center for Teaching and Learning. Available at:

http://bokcenter.harvard.edu/blog/use-mobile-devices-college-classroom (Accessed: 20 November 2017).

Caldwell, J.E. (2007) 'Clickers in the large classroom: current research and best-practice tips.' Life Sciences Education, 6(1), 9-20.

Graves, T. (2008) Semper and Score: Enhancing enterprise effectiveness. Colchester: Tetradian Books.

Hedgcock, W. H. and Rouwenhorst, R. M. (2014) 'Clicking their way to success: using student response systems as a tool for feedback.' Journal for Advancement of Marketing Education, 22(2), 16-25.

Kay, R. H. and LeSage, A. (2009) 'Examining the benefits and challenges of using audience response systems: A review of the literature.' Computers \& Education, 53(3), 819-827.

Keough, S. M. (2012) 'Clickers in the Classroom: A Review and a Replication.' Journal of Management Education, 36(6), 822-847.

Nielsen, K. L., Hansen, G. and Stav, J. B. (2013) 'Teaching with student response systems (SRS): lecturer-centric aspects that can negatively affect students' experience of using SRS.' Research in Learning Technology, 21.

Sana, F., Weston, T. and Cepeda, N. J. (2013) 'Laptop multitasking hinders classroom learning for both users and nearby peers.' Computers \& Education, 62, 24-31.

Traxler, J. (2010) Students and mobile devices. Alt-j, 18(2), 149-160. 